\title{
REAL ESTATE FOR THE AGEING SOCIETY - THE PERSPECTIVE OF A NEW MARKET
}

\author{
Jan Kazak, PhD \\ Department of Spatial Economy \\ Wroctaw University of Environmental and Life Sciences \\ e-mail: jan.kazak@upwr.edu.pl
}

Joost van Hoof, PhD

Centre of Healthcare and Technology

Fontys University of Applied Sciences

e-mail: jvhoof1980@hotmail.com

\section{Małgorzata Świąder, MSc \\ Department of Spatial Economy \\ Wroctaw University of Environmental and Life Sciences \\ e-mail:malgorzata.swiader@upwr.edu.pl}

\author{
Szymon Szewrański, DSc \\ Department of Spatial Economy \\ Wrocław University of Environmental and Life Sciences \\ e-mail: szymon.szewranski@upwr.edu.pl
}

\begin{abstract}
Currently, one of the key challenges on a global scale is the issue of an ageing society. The UN predicts that the number of people aged 60 and over will double by 2050 and treble by 2100 . In the coming years, the demand for real estate that addresses the specific needs of older people will increase both qualitatively and quantitatively. Therefore, two main questions arise: What are the architectural features of real estate required to accommodate for the needs of an ageing society? Which European Union countries seem to have the highest and lowest potential to create a segment of the real estate market focused on older people? This paper contains a research overview in the field of the built environment for older people and case studies of different policies established by public authorities from past decades. The potential for real estate for an ageing society in EU countries was determined on the basis of variables collected by the UNECE. The results also enable assumptions to be made on which factors may influence future development in this area. Due to global climate changes combined with the urbanization process and resulting deterioration of air quality, heat island effect or poor accessibility to open areas, the ageing society will have to face the problem of adapting to these new conditions. Therefore, the authors assume that this will have a significant impact on the relocation of this age group on the real estate market in the future. The conclusions of the research contribute to general discussion on new trends in the real estate market and the assessment of future investments in real estate.
\end{abstract}

Key words: real estate for ageing society, ageing in place, real estate market, home modifications, home adaptations.

JEL Classification: $R 31, I 15, R 20$.

Citation: Kazak J., van Hoof J., Świąder M., Szewrański S., 2017, Real Estate for the Ageing Society - the Perspective of a New Market, Real Estate Management and Valuation, vol. 25, no. 4, pp. 13-24.

DOI: $10.1515 /$ remav-2017-0026 


\section{Introduction}

The ageing of society has been a focus of research since the 1960s (MicHAEL et al. 2006). As population ageing becomes increasingly visible in our societies, the topic of ageing has become a domain of international discussions and research throughout the spectrum of various disciplines: service provision (i.e., transportation, health services), social interventions (i.e., social care and participation), as well as the built environment (i.e., housing, urban planning and real estate) (BUFFEL and PHILLIPSON 2016). The increased interest in the issue of ageing is connected with the growing importance of conditions for older people in the community, such as the availability of professional care and social support coming under pressure due to financial and labor market constraints (CHEN et al. 2016; HUI and YU 2009). This situation is encountered on a global scale, although differences exist between individual countries in terms of the available resources and applied solutions (BUFFEL and PHILLIPSON 2016). Moreover, the situation of the ageing society may be additionally complicated by phenomena such as gentrification (FORYŚ 2013), spatial segregation (ŚWIĄDER et al. 2006) or the reduction of income (PRZYBYŁA 2013).

When referring to the ageing of the population, a threshold is often set when people reach the chronological age of 65. In many countries, this is the legal age for retirement, although this age is rising, particularly in Western European countries, as older adults today are expected to participate in society and are in better physical health than previous generations. In 1950, the cohort of people aged 65 and over accounted for $7.7 \%$ of the population of OECD countries. In 2010, this percentage increased to as much as $17.8 \%$. It is estimated that this percentage will increase to $25 \%$ by the year 2050. Furthermore, for the first time in history, there will be more seniors than children. An increase of 143 million seniors is expected by 2050 ( 57 million by 2025, and another increase of 86 million between 2025 and 2050) (FADDA et al. 2010). At the same time, the median age in Europe increased from 36.0 in 1993 to 41.9 years in 2013 (SMALIUKIENE and TVARONAVIČIENE 2014). Taking this into account, there is an urgent need to create "age(ing)-friendly cities and communities" (BUFFEL AND PHILLIPSON 2016). As highlighted in a report by the Organization of Economic Cooperation and Development, there is a need "to pay more attention to local circumstances to understand ageing and its impact" (OECD 2015). In relation to daily life and housing conditions of the older population, it is important to understand that the majority of older people are home owners, with this figure being higher than that of the average population (GURDGIEV 2005). These arguments are important in the context of the analysis of demand for real estate, as the age distribution within the population determines the types of real estate that are sought (GLICKMAN 2014). Therefore, there is a need to adopt the current demographic situation to the housing market (KŁUSEK 2016). The ageing population has a profound impact on the real estate market, which is transforming in terms of the availability of retirement accommodation for older adults and accessible, adapted, single-floor dwellings (PWC 2014).

\section{The real estate market and housing for older people}

The real estate sector is a versatile domain that offers a wide range of properties which are similar in terms of a specific feature. Classifications of the real estate market can refer to the function of the real estate (residential, commercial, industrial, agricultural, etc.), spatial range (local, regional, national, international), criteria of acquired property rights (rental market, deposit market), public interventionism (public or private), value criteria, quality criteria, and so on (KUCHARSKA-STASIAK 2006). The real estate sector can also refer to a narrow group of potential customers (for instance, users or buyers), who play a role on a given market (ANGHEL and HRISTEA 2015). Each classification can be used for different purposes. As a result, we can define some specific segments of the real estate market, which should not be mistaken with real estate segmentation inside one specific group of properties (BERACHA et al. 2017). Real estate market segmentation uses values and features of property attributes in order to divide them in separate classes inside one group or segment (FRUKACZ et al. 2011, HATEMI-J et al. 2014). Discussions concerning real estate for an ageing society would refer, therefore, to this segment of the real estate market.

As mentioned in the introduction, the percentage of home owners in the group of older people is higher than average. These people usually have a strong connection with the environment they know well, spending their last years in a familiar setting, which, in turn, influences their self-confidence and independence. The situation when older people are able to stay at their homes, without moving to an institutional care facility, is called "ageing in place" (VAN HOOF 2010). Being able to age in place is 
even more important in the case of physical limitations and cognitive limitations posed by the dementia syndrome. Research shows that, as long as people are able to stay at their own homes, they are likely to do so. However, it is not possible to remain living at home in every case, and institutionalization becomes an option. Some people require nursing care which can be provided in nursing homes, which, ideally, should be a home away from home (EIJKELENBOOM et al., 2017). Therefore, in order to define which portion of the real estate segment is suitable for the ageing society, it is necessary to assess existing buildings and architectural solutions which make them friendly for this age group. In addition, one should also consider the strengths of nursing home architecture, which may be implemented in individual homes.

\section{Features of real estate for the ageing society}

Although the biological ageing process may take place in good health and is not, per definition, a precursor for dependency, it may also be accompanied by an increased risk of chronic diseases and physical and cognitive impairments. The age-related changes in health and daily functioning, new visions on health care and the emancipation of older adults have had an impact on individual living requirements as well as consequences to the housing market and public housing task. National governments prioritize ageing in place - in combination with a sufficient amount of professional home care - as a strategy for maintaining autonomy, independence, a sense of identity, and quality of life, as well as for maximizing financial resources and for decreasing the demand for institutional care (nursing homes) (VAN HOOF 2010). The vast majority of older people want to remain living in the community, as their own home and possessions represent what they have accomplished throughout life and provide a quality of life that cannot be substituted in an institutional setting (COHEN and DAY 1993). Ageing in place can be defined as the ability to live in one's own home for as long as they feel confident and comfortable within it. In order to enable older adults to age in place, (i) persons receive support for (instrumental) activities of daily living and physical activity. Also, homes are being modified in terms of (ii) architecture and (ii) technological solutions (STEFANOV et al. 2004). These interventions may, to a certain extent, facilitate ageing in place, depending on the health status of the occupants.

The most frequently encountered measures in and around the home are adaptations to improve the accessibility of the home for people with impaired mobility (removal of thresholds, installation of stair elevators in multi-storey houses, the replacement of bath tubs with level-access showers, and so on). Apart from these expensive measures, simple bars and handrails can improve accessibility and mobility for older people (VAN HOOF et al. 2010, VAN HOOF et al. 2013). Contrary to popular belief, wheelchair accessible kitchens are not among the most frequently encountered modifications to dwellings. All of these measures are often carried out consulting an occupational therapist in order to install items based on anthropometric data (i.e., at the right height). In multi-storey housing or apartment blocks, the absence of an elevator can have severe consequences to accessing and exiting one's home if mobility is impaired. Another concern is the lack of storage space for wheeled walkers and mobility scooters (including a place to charge batteries) when living in an apartment block with limited space to maneuver in corridors. Overall, gardens and the maintenance they require are a main reason for moving.

Especially in terms of impairments and disabilities, older adults do not comprise a homogeneous population. The existing dwelling stock is not sufficiently adjusted toaccommodate for persons with a multitude of diseases and disorders, of which older adults with dementia make up a significant and growing group. This increasing group of people has such specific needs in terms of housing and care that they pose great challenges to the various national housing and care systems found in Europe. Throughout Europe, the majority of people with dementia live at home, where they are, to a large extent, dependent on family care, which is supplemented by professional care (VAN HoOF et al. 2009). Being able to age in place requires a wide range of solutions, including specific home modifications and assistive technologies that address the needs of people with dementia. Dementia is a syndrome that impacts all aspects of daily life. Many everyday modifications and technologies form a solution primarily for mobility problems that often stem from biological ageing and specific disorders. This means that the homes that have undergone modifications or have been designed according to the needs of older adults, such as single-level homes, cannot fully support people with dementia and their fellow caretakers. Currently, persons with dementia are offered home modifications for impaired 
mobility and sometimes poor eyesight. This is not sufficient, as the solutions (and policies) do not address impaired cognition and other problems associated with dementia. However, the United Nations (2002) recognizes the need for programs to help people with dementia live at home for as long as possible. Easily accessible and safe housing and living environments are among these services. According to the United Nations (2002), it is important that older persons are provided, where possible, with adequate choices of where to live, a factor that needs to be built into policies and programs.

\section{Problems faced by family caretakers in relation to housing}

CHARNESS and HOLLEY (2001) concluded that "[t]he majority of persons with Alzheimer's disease dwell at home [...]. So, when considering design issues, the first stop is going to be at the home. Because many persons with Alzheimer's disease will progress to institutional care, the final stop for effective design is going to be at nursing homes or at assisted living housing." The increasing group of older people with dementia and their family caretakers poses great challenges in terms of creating suitable living environments and appropriate housing facilities. As many of the family caretakers of senior citizens are, themselves, over 65 years old, they too may be coping with health problems connected with biological ageing or chronic diseases. On the level of an individual occupant, this may lead to home modifications and retrofitting, moving, or simply living in unfavorable conditions, which might pose a hazard to their quality of life. Family caretakers themselves need support in terms of the accessibility of dwellings and poor vision, and may ask for environmental interventions that support care. DUIJNSTEE (1992) concluded that the home environment has a profound influence on caring for persons with dementia, and this, of course, is also experienced by family caretakers. Whether the home environment facilitates or hinders care depends largely on the behavior and capabilities of the person with dementia. In short, the fewer barriers there are at home, the easier and less burdensome family care can be. DUIJNSTEE (1992) presumed that a practical living situation can decrease the problems faced by family caretakers. A small number of national publications, including works by the Ministry of Community and Social Services of Ontario, Canada (MINISTRY OF COMMUNITY AND SOCIAL SERVICES 1990) and works from Belgium (ROMMEL ET AL. 1998) and the Netherlands (BLOM ET AL. 2000) provide family caretakers with practical information on how to implement environmental interventions at home. Often, technology is considered as a solution to support ageing in place; assistive devices, for instance, are used to improve mobility. In the case of dementia, careful reconsideration of technology as a means of support is in place. On one hand, the complexity of technology at home plays a role in the loss of abilities, and caretakers emphasize the disabling effects of contemporary technology (GALASKO 1998, HAGEN et al. 2004). On the other hand, technological solutions may also offer support. A variety of new technological solutions, including assistive technologies and home automation systems, are emerging within the domain of health care. The latter include inexpensive support systems, which allow care and health centers to remotely observe and help their clients (VAN HoOF et al. 2017). Nevertheless, there are still many questions concerning the efficacy, benefits and acceptance of such systems, particularly in dementia care.

\section{Methodology and data sets}

The aim of the study is to define an age-friendly real estate sector in terms of architectural and technological features that should be included in real estates, as well as to assess the potential of real estate for the aging society on the market in EU countries. The study includes a revision of scientific outcomes from past decades, which is presented in Section 3 and 4, as well as Indicator-based spatial analysis of future perspectives.

The potential assessment of EU countries in relation to independent living of older people in individual real estate was based on variables collected by the UNECE within the framework of Active Ageing Index (AAI) calculations. So far, the indicator has been prepared for 2010, 2012 and 2014 . It consist of 22 variables describing factors including employment rates (in different age intervals), the population aged 55+ that is engaged in voluntary work (for organizations; childcare, care for older people or people with disabilities/limitations; various forms of political activities), a healthy lifestyle (undertaking physical exercise and sports, regular medical and dental examination), safety conditions (no risk of poverty; feeling safe in their neighborhood), independent living (living in single person or two-person households; receiving education and training) and others relating to the quality of life (years of a healthy life in life expectancy; social connections; mental well-being). All indicators in AAI 
were measured based on public statistics (e.g. Eurostat) or surveys and interviews (in this case, the questionnaire was the same for each country), depending on the variable being measured. The criterion of comparability of indicators across all countries, was achieved by using the same data sources. The prime datasets used to estimate active ageing indicators were EU-SILC (Survey of Income and Living Conditions), the EU-LFS (the Labor Force Survey) and the European Quality of Life Survey (EQLS). Most values were obtained for 2008, 2010 and 2012, however, there are some infrequent exceptions in some of the countries. Moreover, there was no predefined sample size for each country (ZAIDI et al. 2013). There are some limitations and critiques of AAI. It is mentioned, for instance, that AAI is an incomplete tool for policymakers as it does not measure older people's capabilities in a specific field. As a result, we do not know if actions in one sphere will influence a change as benchmarks for each country might be different (DE SÃO JOSÉ et al., 2017). However, the authors decided to use the AAI due to its comparability between the countries, especially that we do not assess which country can expand their real estate stock for the market of an ageing society but only evaluate in which country the current situation allows real estate professionals to focus on this group of clients.

All variables tested in the research are justified in scientific literature due to their cause-effect relation in reality. The physical exercise indicator illustrates the percentage of seniors involved in sports activities and undertaking physical exercise almost every day. Good physical condition allows people to stay active and independent in their social environments. The impact of moderate physical activity on health has been well-recognized. Floegel and Perez (2016) investigated the positive relation between physical activity and health-related quality of life factors. They conclude that older adults suffering from heart disease may improve their level of fitness and reduce mortality. Albuquerque et al. (2017) showed that physical activity can be a major element of satisfactory well-being as well as improving the mental skills of older people. On the other hand, the physical inactivity of senior citizens is one of the risk factors for many chronic diseases (BEALs et al., 2017). Good access to health and dental care is essential for an active, healthy and socially independent life led by older people (MAGILVY et al., 2000, MOSALLANEZHAD et al., 2017). The older adults with chronic health problems or impairments suffer more health care inequalities and undergo acts of discrimination (ALLERTON and EMERSON, 2012). Living in remote or rural areas can also implicate poorer access to the provision of health services (FARMER et al., 2010, URSULICA, 2016, RUSHWORTH et al. 2017). Geographic discrimination is additionally compounded by transport accessibility and the financial capability to pay for a service (SOMENAHALLI and SHIPTON, 2013). Older people with unstable or low income suffer from high out-of-pocket payments for healthcare (JEON et al., 2017). Thus, relative median income as well as the risk of poverty and lack of severe material deprivation are the next three significant indicators of independent living. They are designed to measure financial security and economic independence, as the basis for health and a better life without the risk of poverty (MASKILEYSON, 2014, ADENA and MYCK, 2014). A very important factor of life quality is feeling safe in one's physical environment and not worrying about becoming a victim. Neighborhood safety remains important, especially for the health and wellbeing of seniors (WON et al., 2016). Stronger cohesion with the neighborhood implicates a higher level of mental health and well-being of older inhabitants (GALE et al., 2011). The conditions of the built-up environment interact with social structures. This system affects the senior citizens' quality of life in a complex manner (ENGEL et al., 2016). A cohesive and inclusive society relies on the knowledge and competence of individuals. Thus, lifelong learning was designed as an indicator of all education or trainings addressed to older people, making them more active in a knowledge-based society (DE DONDER et al., 2014).

All of the AAI variables described above have an impact on the possibility of successfully ageing in place, and, therefore, continuing to live in one's own home. However, some variables seem to describe the potential of age-friendly real estate in greater detail. The correlation between seven variables describing living conditions and the rate of independent living was statistically tested by the Pearson correlation coefficient $(r)$ in order to identify which of those conditions may have the biggest impact on the independent living of older people.

\section{Results}

The living conditions of ageing adults vary across EU countries depending on a range of factors. To monitor those differences, the UNECE started to calculate AAI. The reference variable assumed by 
this research as a measure of ageing in place was independent living arrangements from AAI. This factor presents the percentage of persons aged 75 and older living in single or two-member households. In some cases, living in single or two-member household may take place in a different household than where older people had been living for many years. However, as the aim of the research is to analyze the potential of real estate for an ageing society (including all seniors able to function in their own homes), independent living was assumed to be relevant. Seven variables from the third group called independent, healthy and secure living were analyzed according to their correlation with the reference factor. Correlation between each variable was divided into the years: 2010, 2012, 2014. The results have been presented in Figure 1 and Table 1.

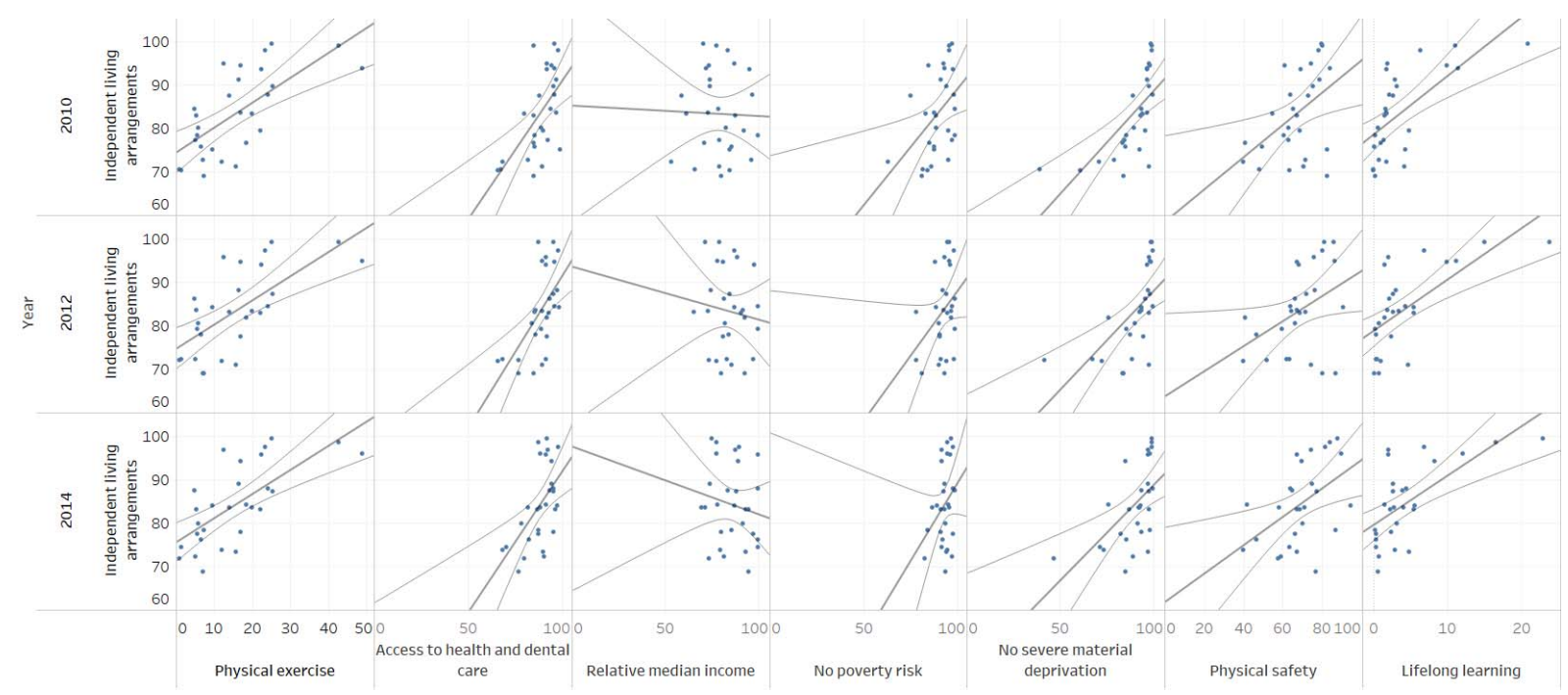

Fig. 1. Correlation of independent, healthy and secure living variables. Source: own study.

Table 1

Correlation of independent, healthy and secure living variables

\begin{tabular}{lccc}
\hline & Variable & \multicolumn{2}{c}{ Correlation with independent living arrangements } \\
\cline { 2 - 4 } & 2010 & 2012 & 2014 \\
\hline Physical exercise & $0.680552^{*}$ & $0.669330^{*}$ & $0.692999^{*}$ \\
\hline Access to health and dental care & $0.598611^{*}$ & $0.602820^{*}$ & $0.556155^{*}$ \\
\hline Relative median income & -0.028862 & -0.113985 & -0.161479 \\
\hline No poverty risk & $0.452286^{*}$ & 0.348493 & 0.307266 \\
\hline No severe material deprivation & $0.662531^{*}$ & $0.608369^{*}$ & $0.561542^{*}$ \\
\hline Physical safety & $0.465370^{*}$ & $0.399439^{*}$ & $0.483812^{*}$ \\
\hline Lifelong learning & $0.652934^{*}$ & $0.668653^{*}$ & $0.656160^{*}$ \\
\hline
\end{tabular}

* - the results are statistically significant.

Source: Own study.

The most noticeable results occurred for relative median income. This variable presents the ratio of the median equivalized disposable income of people aged $65+$ to the median equivalized disposable income of those aged below 65. There is no statistical significance for all three years and, at the same time, no positive $r$ results were noticed. Therefore, there does not seem to be any impact of income when it comes to ageing in place across the EU. The strongest correlation characterized independent living arrangements with: physical exercise (percentage of population aged 55+ who engage in physical activity and sport at least five times a week) and lifelong learning (percentage of older persons aged 55- 
74 who had received education or training in the 4 weeks preceding the survey). The results for all of these factors are statistically significant, with their $r$ value falling in the range between 0.65 and 0.69 , depending on the year. Despite the correlation level, the question that remains is the cause-effect relation between those variables. Physical and mental activities may influence older people remaining in good (physical and mental) condition and, therefore, allows them to complete everyday tasks and remain independent. The assumption that good physical and mental condition is the main driver of ageing in place could be verified by further social research.

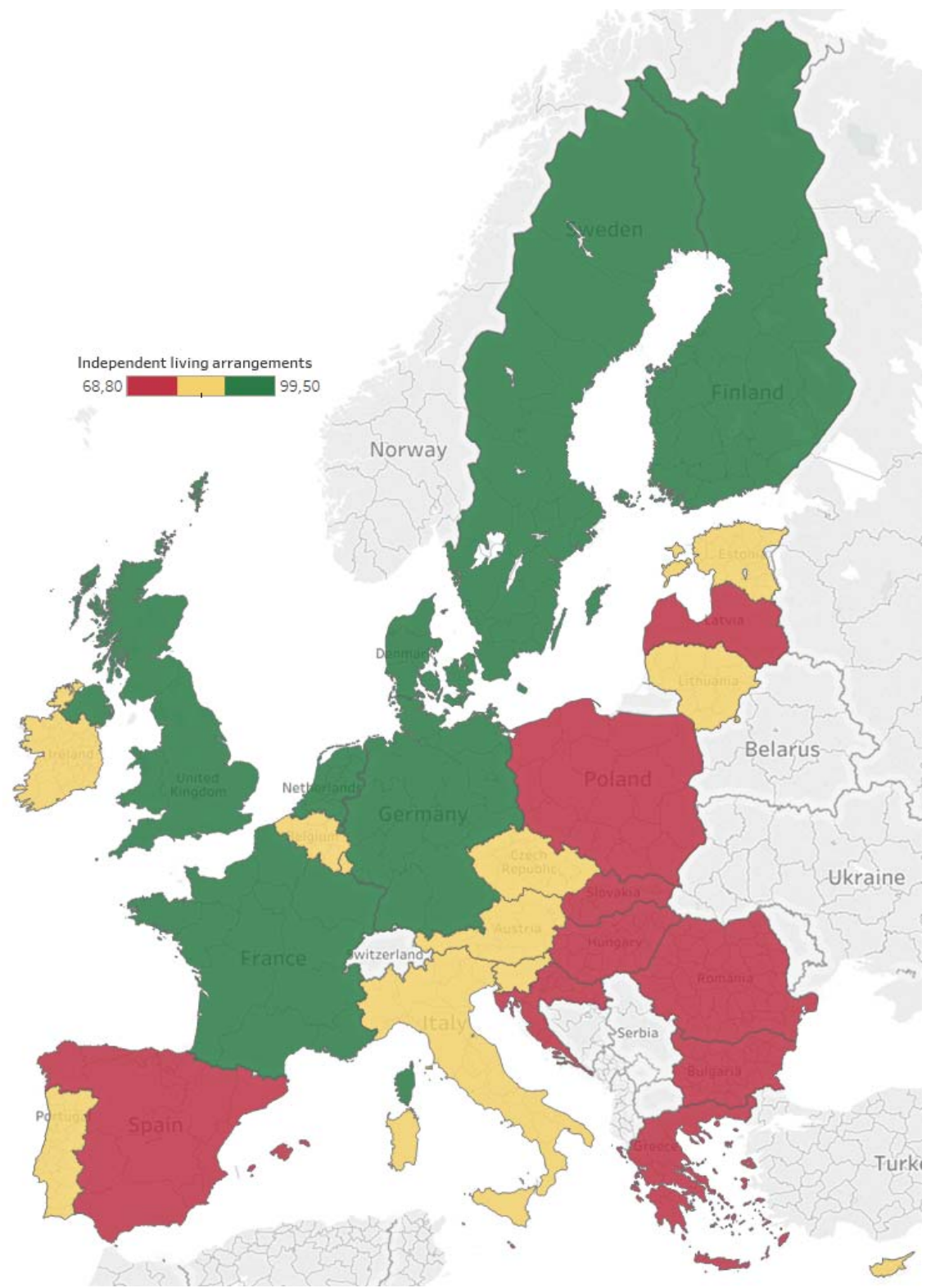

Fig. 2. Percentage of population living independently in EU countries in 2014. Source: Study based on AAI 2014: Analytical Report (UNECE 2015).

The coefficient of multiple correlation (Multiple R) was computed using multiple regression analysis. Significant relationship between the variables had been found only for aggregated data from all the years, with the value of multiple $\mathrm{R}$ being 0.809 . Obtained statistics indicate that only the variables: physical exercise, access to health and dental care and lifelong learning are independent and should be used in further multivariate regression modelling. In that regression model, the coefficient of multiple determination was estimated at 0.676 , and residuals are distributed normally.

All countries have been grouped with the use of the $k$-means clustering algorithm. We used Lloyd's algorithm with squared Euclidean distances to compute the $k$-means clustering for each $k$. All 8 
independent variables were applied. The optimal number of classes was 3 . The $1^{\text {st }}$ cluster consisted of 18 items, $2^{\text {nd }}-6$, and $3^{\text {rd }}-3$. One country was an outlier. Differences between clusters were estimated by values of the between-group sum of squares (5.4507) and within-group sum of squares (6.2285).

Irrespective of the factors influencing ageing in place, the current state of persons aged 75 and older living in single or two-member households was analyzed. This value varies among EU countries from just under $69 \%$ in Poland to over $99 \%$ in Denmark. The range of values in all the countries was divided into thirds, with these presented in Figure 2, according to their independent living rates. A business intelligence system was used for visualizing the results, namely Tableau (SZEWRAŃSKI et al. 2017).

The top 5 countries in the ranking are: Denmark (99.5\%), Sweden (98.7\%), the Netherlands (97.5\%), Germany $(96.8 \%)$ and Finland $(96.0 \%)$. The lowest percentages were noted in: Latvia $(74.4 \%)$, Spain $(73.4 \%)$, Slovakia $(72.3 \%)$, Bulgaria $(71.9 \%)$ and Poland $(68.8 \%)$. The ranking of independent living arrangements over the three analyzed years does not change significantly. The factor shows the highest values to characterize mainly member states of the EU which had joined prior to 2000. An exception to this is noticeable in the group of Mediterranean countries. All countries that joined the EU after 2000 have a medium or low percentage of persons aged 75 and older living in single or twomember households. Nevertheless, in future research in this field, it could be analyzed if this differentiation is connected only with living and health conditions or if it is also influenced by sociocultural aspects. Despite the reason for factor diversification, it ought to be highlighted that most of the EU population lives independently, so there is a need to develop real estate properties accounting for the needs of older adults, regardless of whether or not they choose to change their homes. Rising to the current and future expectations of real estate owners or users by developing homes which are more accessible and accounting for technological as well as organizational solutions to improve their functionality will give the ageing society a chance to age in place and improve the quality of these people's lives.

\section{Discussion and conclusions}

The development, occupancy and maintenance of buildings is a complex process that occurs within a dynamic context. This complexity increases when the design process concerns buildings for specific user groups, such as older people (with dementia) as discussed in this paper. This complexity stems partly from the interdisciplinary character of the design process, involving a multitude of professionals that work together in creating a building or that are responsible for the design, construction, operation and maintenance of the building over time (VAN HoOF et al. 2015). All of these professionals contribute their own expertise to the design process, and, in this contribution, operate mainly within the limitations of what is known and familiar to them.

This complexity also stems from the functionality that the users of buildings demand from the design, for instance, improving well-being and care support, including feeling at home or having enough space for easy mobility in the bathroom. And, in turn, complexity increases as a result of changes in for the required performance levels over time, which stems from (i) the increasing sense of quality among the occupants and users, and from (ii) advanced understanding in general. This advanced understanding becomes clear in the case of health care facilities or homes for people with special needs, where designers are starting to understand the needs of the users of such buildings.

The design, operation and maintenance of health care facilities are particularly complex, as criteria are constantly evolving (VAN HOOF et al. 2015). Discussions about the importance of the built environment for delivering health care extend at least as far back as Hippocrates (400 BC) (CODINHOTO et al. 2009). Current climate changes and their impact on the health of an ageing society play a significant role in relocation on the real estate market. Older people are, for instance, forced by the situation to move from apartments on the top floors of buildings to the ground floor in order to reduce heat risk (TOMLINSON et al. 2011) or physical barriers. Within the domain of health care and medicine, professionals work based on evidence-based practice, meaning that treatment and interventions should be supported by scientific evidence, and that the solutions or interventions chosen are the best answer to the identified problem. Thus, the design of buildings in which medical treatment and interventions take place should be in compliance with evidence-based practice, and the same can be said about housing facilities for people with dementia. Brawley (2005) mentions that "just as medicine has increasingly moved toward evidence-based medicine, healthcare design is moving toward evidence-based design. Increasingly guided by rigorous research linking characteristics of the physical 
environment to resident outcomes, the focus of evidence-based design is not on creating care settings that are nicer or glitzier than traditional residential and nursing home settings, but rather on creating environments that actually help residents remain as healthy and independent as possible, be safer, and help staff do their jobs better. The goal is improving outcomes and continuing to monitor the success of designs for subsequent decision making." There is a need for an integrated building approach that optimizes values for all stakeholders involved in the building process and the building's lifespan. This calls for a framework that can combine the needs within the domain of health care with solutions from the domain of real estate development and maintenance. The real estate sector has a significant role to play in finding solutions to ever-growing challenges in terms of housing needs posed by the ageing population. Therefore, it is important to establish which environmental solutions, such as home modifications and facilitators in the built environment, contribute to ageing in place and the well-being of older citizens, in order to promote self-care and independence for as long as possible.

AAI data prove that most of older people in the EU live independently, and thus they probably prefer to age in place. In order to improve the quality of their lives, there is a potential to focus on older people as important clients (current or future) of real estate market. This means that there is a need to develop real estate properties which are more accessible, accounting for technological and organizational solutions to improve the functionality they offer their owners or users in the future. The potential of the real estate market for an ageing society is relatively high at the moment in most countries which had joined the EU prior to 2000. The majority of countries which joined the EU after 2000 have a lower potential in this area. Improving the physical and mental capabilities of seniors may influence their ability to live independently. This may, in turn, require both robust and flexible solutions from the real estate sector to provide solutions for an ageing society.

\section{References}

AdenA, M., MycK M., 2014, Poverty and Transitions in Health in Later Life, Social Science \& Medicine, $116,202-210$.

Albuquerque A. P. A., Borges-Silva F., Da Silva Borges E. G., Pereira A. P., Dantas E. H. M., 2017, Physical Activity: Relationship to Quality of Life and Memory in Older People, Science \& Sports.

AlLERTON L., EMERSON E., 2012, British Adults with Chronic Health Conditions or Impairments Face Significant Barriers to Accessing Health Services, Public Health, 126, pp. 920-927.

Anghel I., HRISTEA A. M., 2015, Some Considerations Regarding the International Real Estate Market Present and Future Predictions, Procedia Economics and Finance, No. 32, pp. 1442-1452.

Beals J. W., Shy E. L., Burd N. A., 2017, Chapter 9 - Interaction Between Diet and Physical Activity in Older People A2 - Raats, Monique M. In: GROOT, L. C. P. G. M. D., ASSELT, D. V. (eds.) Food for the Aging Population (Second Edition), Woodhead Publishing.

BerachA E., HARdin W. G., SKIBA H. M., 2017, Real Estate Market Segmentation: Hotels as Exemplar, The Journal of Real Estate Finance and Economics [in press].

Blom M., TJAdens F., WiTHAGEN P., 2000, Weten van vergeten (Knowing About Forgetting), NIZW, Utrecht, The Netherlands [in Dutch].

BRAWLEY E.C., 2005, Creating Caring Environments, Alzheimer's Care Quarterly, 6(4), pp. $263-264$.

Buffel T., Phillipson C., 2016, Can Global Cities Be 'Age-Friendly Cities'? Urban Development and Ageing Populations, Cities 55, pp. 94-100. DOI: 10.1016/j.cities.2016.03.016.

CHARNESS N, HOlley P., 2001, Human Factors and Environmental Support in Alzheimer's Disease, Aging \& Mental Health, vol. 5 (Supplement 1), pp.65-73.

CHEN J., WANG Y., Wen J., FANG F., SONG M., 2016, The Influences of Aging Population and Economic Growth on Chinese Rural Poverty, Journal of Rural Studies 47, pp. 665-676. DOI: 10.1016/j.jrurstud.2015.11.002.

Codinhoto R., Tzortzopoulos P., Kagioglou M., AOuAd G., CoOper R., 2009, The Impacts of the Built Environment on Health Outcomes, Facilities, 27(3-4), pp. 138-151.

COHEN U., DAY K J., 1993, Contemporary Environments for People with Dementia, The Johns Hopkins University Press, Baltimore, MD, USA - London, UK.

De Donder, L., Brosens, D., De Witte, N., Buffel, T., Dury, S., Smetcoren, A.-S., Verté, D., 2014, Lifelong Learning in Old Age: Results from the Belgian Ageing Studies, Procedia - Social and Behavioral Sciences, 116, pp. 513-517.

DUIJNSTEE MSH, 1992, De belasting van familieleden van dementerenden, Dissertation, Katholieke Universiteit Nijmegen, Nijmegen, The Netherlands [in Dutch]. 
EIJKELENBOOM A., VerbeEK H., FELIX E., VAN HOOF J., 2017, The Architectural Factors Influencing the Sense of Home in Nursing Homes: An Operationalization for Practice, Frontiers of Architectural Research 6(2) doi: 10.1016/j.foar.2017.02.00.

Engel L., CHudyK A. M., Ashe M. C., MCKAy H. A., Whitehurst D. G. T., BRyAn S., 2016, Older Adults' Quality of Life - Exploring the Role of the Built environment and Social Cohesion in Community-Dwelling Seniors on Low Income, Social Science \& Medicine, 164, pp. 1-11.

Fadda G., Cortés A., Olivi A., TOVAR M., 2010, The Perception of the Values of Urban Space by Senior Citizens of Valparaiso, Journal of Aging Studies 24 (4), pp. 344-357. DOI: 10.1016/j.jaging.2010.07.001.

FARMer J., PhiliP L., King G., FARrington J., Macleod M., 2010, Territorial Tensions: Misaligned Management and Community Perspectives on Health Services for Older People in Remote Rural Areas, Health \& Place, 16, pp. 275-283.

Floegel T. A., PEREZ G. A., 2016, An Integrative Review of Physical Activity/Exercise Intervention Effects on Function and Health-Related Quality of Life in Older Adults with Heart Failure, Geriatric Nursing, 37, pp. 340-347.

FORYŚ I., 2013, Gentrification on the Example of Suburban Parts of the Szczecin Urban Agglomeration, Real Estate Management and Valuation, Vol. 21, No. 3, pp. 5-14.

FrukACZ M., JASIŃSKA E., PREWEdA E., 2011, Real Estate Market Segmentation for Chosen Ground Immobility of Urban-Rural Municipalities District of Krakow, Infrastructure and Ecology of Rural Areas, No. 4/2011, pp. 163-172.

GALASKO D., 1998, An Integrated Approach to the Management of Alzheimer's Disease: Assessing Cognition, Function and Behaviour. European Journal of Neurology, 5 (Supplement 4), pp. 9-17.

Gale C. R., Dennison E. M., CoOPer C., SAYER A. A., 2011, Neighbourhood Environment and Positive Mental Health in Older People: The Hertfordshire Cohort Study, Health \& Place, 17, pp. 867-874.

GLICKMAN E. A., 2014, Chapter 2 - Market Analysis. in: An Introduction to Real Estate Finance, pp. 25-49.

GuRdGIEV C.T., 2006, Owner-Occupied Housing in a Model of Exchange Rate Determination, Journal of Housing Economics 15, pp. 217-229. DOI: 10.1016/j.jhe.2006.09.005.

Hagen I., Holthe T., Gilliard J., Topo P., Cahill S., Begly E., Jones K., Duff P., Macijauskiene J., Budraitiene A., BJørneby S., Engedal K., 2004, Development of a Protocol for the Assessment of Assistive Aids for People with Dementia, Dementia, 3(3), pp. 281-296.

HATEMI-J A., RocA E., AL-SHAYEB A., 2014, How Integrated are Real Estate Markets with the World Market? Evidence from Case-Wise Bootstrap Analysis, Economic Modelling, No. 37, pp. 137-142.

VAN Hoof J., 2010, Ageing-in-Place: the Integrated Design of Housing Facilities for People with Dementia, Dissertation, Eindhoven University of Technology, Eindhoven, the Netherlands.

VAN HoOf J., Blom M.M., POST H.N.A., BASTEIN W.L., 2013, Designing a 'Think-Along Dwelling' for People with Dementia: A Co-Creation Project Between Health Care and the Building Services Sector, Journal of Housing for the Elderly 27(3), pp. 299-332. DOI: 10.1080/02763893.2013.813424.

VAN HOOF J., KORT H.S.M., VAN WAARDE H., 2009, Housing and Care for Older Adults with Dementia: A European Perspective, Journal of Housing and the Built Environment, 24 (3), pp. 369-390. DOI: 10.1007/s10901-009-9143-3

VAN HOOF J., DeMIRIS G., WouTERS E.J.M. (EDS), 2017, Handbook of Smart Homes, Health Care and WellBeing, Springer International Publishing, Switzerland.

VAN HOOF J., KORT H.S.M., VAN WAARDE H., BlOM M.M., 2010, Environmental Interventions and the Design of Homes for Older Adults with Dementia: an Overview, American Journal of Alzheimer's Disease and Other Dementias 25(3), pp. 202-232. DOI: 10.1177/1533317509358885.

van Hoof J., RutTen P.G.S., StRuCK C., Huisman E.R.C.M., KorT H.S.M., 2015, The Integrated and Evidence-Based Design of Healthcare Environments, Architectural Engineering and Design Management 11(4), pp. 243-263. DOI: 10.1080/17452007.2014.892471.

Hui E. C. M., YU K. H., 2009, Residential Mobility and Aging Population in Hong Kong, Habitat International 33 (1), pp. 10-14. DOI: 10.1016/j.habitatint.2008.02.001.

Jeon B., Noguchi H., Kwon S., Ito T., TAmiYA N., 2017, Disability, Poverty, and Role of the Basic Liivelihood Security System on Health Services Utilization Among the Elderly in South Korea. Social Science \& Medicine, 178, pp. 175-183.

KLERK MMY., 2004, Zorg en wonen voor kwetsbare ouderen. Rapportage ouderen 2004, (Care and Living for Frail Older Adults. Report Older Adults 2004), The Netherlands Institute for Social Research, The Hague, The Netherlands [in Dutch]. 
KŁUSEK M., 2016, Directions of Development of the Real Estate Market in the Context of Demographic Changes in Poland, World Scientific News 51, pp. 26-35, available online at: www.worldscientificnews.com [27.12.2016].

KUCHARSKA-STASIAK E., 2006, Nieruchomość w gospodarce rynkowej (Real Estate on a Economy Market), Warszawa, Wydawnictwo naukowe PWN.

Magilvy J. K., COngdon, J. G., MArtineZ, R. J., DAvis, R., Averill, J., 2000, Caring for Our Own: Health Care Experiences of Rural Hispanic Elders. Journal of Aging Studies, 14, pp. 171-190.

MASKILEYSON D., 2014, Healthcare System and the Wealth-Health Gradient: A Comparative Study of Older Populations in Six Countries, Social Science \& Medicine, 119, pp. 18-26.

Michael Y. L., Green M. K., FARQuhaR S. A., 2006, Neighborhood Design and Active Aging, Health \& place 12 (4), pp. 734-740. DOI: 10.1016/j.healthplace.2005.08.002.

MiNistry OF COMMUNITY AND SOCIAL SERVICES, 1990, Dementia and Activities of Daily Living. A Report on Technologies and Environmental Design that Can Assist People with Alzheimer Disease and Related Dementias, Toronto, ON, Canada.

Mosallanezhad, Z., Sotoudeh, G. R., Jutengren, G., SAlavati, M., HARMs-Ringdahl, K., WiKMAR, L. N., FRÄNDIN, K. 2017. A Structural Equation Model of the Relation Between Socioeconomic Status, Physical Activity Level, Independence and Health Status in Older Iranian People. Archives of Gerontology and Geriatrics, 70, pp. 123-129.

OECD, 2015, Ageing in Cities, OECD Publishing, Paris, p. 18, DOI:10.1787/9789264231160-en, available online at: http://www.oecd-ilibrary.org/urban-rural-and-regional-development/ageing-incities_9789264231160-en [27.12.2016].

PRZYBYŁA K., 2015, The Impact of the Polish Administrative Reform on the Central Functions of Lower Silesian Cities, Hradecke Ekonomicke Dny 2015, Economic Development and Management of Regions, Vol. 5, pp. 131-137.

PwC, 2014, Real Estate 2020: Building the Future, p. 13, available online at: www.pwc.com/realestate [27.12.2016].

Rommel W., DeclerQ A., De ClerQ J., VAn Audenhove C., LAMmertyn F., 1998, Tussen autonomie en geborgenheid: Dementerende ouderen en hun omgeving (Between Autonomy and Security: Older People with Dementia and Their Environment), Garant, Leuven Belgium/Apeldoorn, The Netherlands [in Dutch].

Rushworth G. F., Cunningham S., Pfleger S., Hall J., Stewart D., 2017, A Cross-Sectional Survey of the Access of Older People in the Scottish Highlands to General Medical Practices, Community Pharmacies and Prescription Medicines. Research in Social and Administrative Pharmacy [in press].

de SÃo José J.M., Timonen V., Filipe Amado C.A., Pereira SAntos S., 2017, A Critique of the Active Ageing Index, Journal of Aging Studies, Volume 40, January 2017, pp. 49-56.

SMAliUkiene R., TVARONAVIČIENE M., 2014, Bridge Employment. An Opportunity for Aging Society, Procedia - Social and Behavioral Sciences 156, pp. 388-391. DOI: 10.1016/j.sbspro.2014.11.208.

SOMENAHALli S., SHIPTON M., 2013, Examining the Distribution of the Elderly and Accessibility to Essential Services. Procedia - Social and Behavioral Sciences, 104, pp. 942-951.

STEFANOV D.H., BIEN Z., BANG W-C., 2004, The Smart House for Older Persons and Persons with Physical Disabilities: Structure, Technology Arrangements, and Perspectives, IEEE Transactions on Neural Systems and Rehabilitation Engineering, pp. 228-250.

ŚWIĄDER M., SZEWRAŃSKI S., KAZAK J., 2016, Spatial-Temporal Diversification of Poverty in Wroclaw, Procedia Engineering, vol. 161, pp. 1596-1600.

SZEWRAŃSKI S., KAZAK J. SYLLA M., ŚWIĄDER M., 2017, Spatial Data Analysis with the Use of ArcGIS and Tableau Systems, I. Ivan et al. (eds.), The Rise of Big Spatial Data, Lecture Notes in Geoinformation and Cartography, pp. 337-349. DOI: 10.1007/978-3-319-45123-7_24.

TOMLINSON C.J., CHAPMAN L., THORNES J.E., BAKER C.J., 2011, Including the Urban Heat Island in Spatial Heat Health Risk Assessment Strategies: A Case Study for Birmingham, UK, International Journal of Health Geographics, 10:42, pp. 1-14. DOI: 10.1186/1476-072X-10-42.

United NATIONS, 2002, Second World Assembly on Ageing, Madrid, Spain. 8-12 April 2002. Political Declaration and Madrid International Plan of Action on Ageing.

UNECE, 2015, Active Ageing Index 2014: Analytical Report, Report prepared by Asghar Zaidi of Centre for Research on Ageing, University of Southampton and David Stanton, under contract with 
United Nations Economic Commission for Europe (Geneva), co-funded by European Commission's Directorate General for Employment, Social Affairs and Inclusion (Brussels).

Ursulica, T. E., 2016, The Relationship between Health Care Needs and Accessibility to Health Care Services in Botosani County- Romania, Procedia Environmental Sciences, 32, pp. 300-310.

WON J., LeE C., FORJuOH S. N., ORY M. G., 2016, Neighborhood Safety Factors Associated with Older Adults' Health-Related Outcomes: A Systematic Literature Review, Social Science \& Medicine, 165, pp. 177-186.

Zaidi A., GASIOR K., HOFMARCher M., LelKes O., MARIN B., ROdRigues R., SCHMidT A., VANHUYsse P., ZolyOMi E., 2013, Active Ageing Index 2012 Concept, Methodology and Final Results, Project: 'Active Ageing Index (AAI)', UNECE Grant No: ECE/GC/2012/003. European Centre Vienna. 